\title{
O GENOCÍDIO ARMÊNIO E SEUS REFLEXOS NA LITERATURA
}

Deize Crespim Pereira'

Aвstract: The history of Armenia in the $20^{\text {th }}$ century is marked by a tragedy: the genocide of approximately 1,500.000 inhabitants of Turkish Armenia by the Ottoman Empire. The goal of this paper is to analyze two main consequences of the Armenian genocide in Armenian literature, namely, the transition from modern (1850-1915) to contemporary literature (1915-), and the formation of Armenian contemporary literature in Diaspora. While Armenian modern literature is largely characterized by militant engagement, aiming to instruct the popular masses so that they could fight for political and social justice and for independence, Armenian contemporary literature produced in Diaspora deals mainly with questions concerning cultural identity of Armenian descendants that were born in Diaspora. We exemplify these trends with excerpts from texts written by two modern authors (Raffi and Daniel Varujan) and two contemporary ones (William Saroyan and Michael J. Arlen).

KeYwords: Modern armenian literature, Contemporary armenian diáspora literature, Armenian genocide. ${ }^{2}$

A história da Armênia é marcada no século XX por um acontecimento trágico: o genocídio de cerca de 1,5 milhão de armênios que habitavam as províncias da Armênia Turca sob domínio otomano.

1 Professora Doutora na área de Língua e Literatura Armênia do Departamento de Letras Orientais da FFLCH - USP.

2 Este artigo é um desenvolvimento da exposição que fiz sobre literatura armênia no debate "Literaturas em conflito: Palestina, Armênia e Rússia no século XX", promovido pelo CAELL e realizado na FFLCH/USP em maio de 2009. 
Este acontecimento tem consequências diretas na literatura. $\mathrm{O}$ período correspondente à literatura armênia moderna vai de 1850 a 1915 . O que se denomina literatura armênia contemporânea são justamente os escritos que surgem a partir de 1915 (cf. SAPSEZIAN, 1994). Este ponto de referência no tempo, convencionalmente usado para estabelecer o limite entre a literatura moderna e a contemporânea, é historicamente motivado pelo genocídio. ${ }^{3}$

Os armênios do mundo todo tomam como data-símbolo do genocídio 0 dia 24 de abril de 1915, quando o governo otomano assassinou duzentos intelectuais armênios em Constantinopla. Como se tratou de um plano premeditado e sistematicamente executado, a matança se iniciou justamente pelos intelectuais, aqueles que poderiam organizar alguma resistência. Há toda uma geração de escritores armênios modernos que perdeu a vida no genocídio. ${ }^{4}$

Este genocídio armênio perpetrado pelos turcos é, no entanto, muito mais longo do que se pensa. Ele se iniciou a partir de alguns conflitos ocorridos

3 Os críticos diferem na delimitação desta data final, que marca a transição da literatura armênia moderna para a contemporânea. Kerouzian e Diniz (1979), por exemplo, adotam outra periodização, considerando o ano de 1890 como o limite entre a literatura moderna e a contemporânea. Os autores não deixam claro quais critérios nortearam a fixação desta data. Eles podem ter considerado tanto questões estéticas, temáticas e linguísticas (i.e. a influência da escola realista; o fato de a língua moderna adquirir, a partir de 1890, sua "forma definitiva"), quanto os conflitos físicos entre armênios e turcos, que tiveram início em 1890 e precederam o genocídio.

A nosso ver, os primeiros critérios citados não são suficientes para caracterizar a transição entre literatura moderna e contemporânea. A língua armênia moderna já tinha se estabelecido como língua literária no período moderno (século XIX). O mesmo pode ser dito com relação à influência da escola realista: o Realismo é visto como uma das correntes que influenciaram os escritores armênios modernos.

Sabemos que a transição entre períodos literários costuma ser explicada principalmente em termos de questões estéticas. O genocídio armênio, no entanto, teve consequências muito mais abrangentes na literatura: ele implicou a morte ou exílio de vários autores modernos, a mudança drástica do contexto onde a literatura é produzida (formação da diáspora armênia) e mudanças temáticas significativas.

4 Hacikyan (2005) nota que este número de duzentas vítimas logo chegou a seiscentas. O método de execução consistia em: desarmar a população, matar os intelectuais, matar os homens jovens e, por fim, colocar mulheres, velhos e crianças para marcharem nos desertos da Síria, numa suposta "deportação" (cf. TOYNBEE, 1916/2003). 
em 1890 - que culminaram nos massacres de 1895-1896-, atingiu o seu ápice em 1915 e se estendeu até o ano de 1923 (MARTINS, 2007).

Como consequência das várias guerras entre otomanos, persas e russos, a Armênia se encontrava, no final do século XIX e início do século XX, sob a dominação de dois Impérios: o Russo na região oriental ("Armênia Russa") e o Otomano na parte ocidental (“Armênia Turca”).

A Armênia Turca estava dividida em seis províncias administrativas (vilaietes). Os armênios que habitavam essa região não dispunham de direitos civis, eram explorados e viviam em condições de extrema pobreza, especialmente nas províncias do interior da Armênia Turca. Vistos como meros servos, eles não tinham sequer direito à propriedade, ainda assim pagavam um número absurdo de impostos (imposto por não ser islâmico, imposto sobre a produção agrícola, imposto sobre cada membro da família, imposto para trabalhar na terra, imposto para casar, etc.) (HACIKYAN, 2005).

Além desta exploração, o governo turco começou a incentivar a migração de tribos nômades curdas para estas regiões. Estas tribos iriam saquear os armênios, estuprar suas mulheres e fazer disto um hábito.

Grande parte da população armênia dessa época era composta por agricultores e pastores. Apesar de todas as injustiças e opressão que vinha sofrendo, ela é descrita como uma população pacífica, inclusive por historiadores britânicos da época (cf. TOYNBEE, 1916/2003).

A população armênia da Armênia Turca não era, no entanto, homogênea. Havia uma classe de mercadores e banqueiros e uma elite intelectual educada na Europa e imbuída do ideal democrático. Sob a influência do nacionalismo europeu, esta elite intelectual vai criar movimentos que lutam pela independência do jugo estrangeiro e por reformas nas condições de vida dos armênios da Armênia Turca. Havia uma liderança tanto em Constantinopla (capital do Império Otomano), como na Armênia Russa, para melhorar as condições dos armênios nas províncias ocidentais.

É neste contexto histórico que surge uma literatura engajada, militante, que busca a conscientização do povo, para que ele possa lutar por justiça social e política e pela libertação do jugo estrangeiro. Trata-se da literatura armênia 
moderna. Entre os autores mais representativos deste período e destas tendências, estão Raffi e Daniel Varujan. ${ }^{5}$

Raffi (Hagop Melik Hagopian) (1835-88) compôs, no final do século XIX, uma novela histórica intitulada Khent ("Louco"), na qual retrata o contexto político e social imediatamente anterior ao genocídio. A título de ilustração, transcrevemos, a seguir, três trechos desta obra:

Lindo cenário se descortinava diante de seus olhos. Estava sentado no pé da montanha e o solo, devido à erosão, estava coberto de seixos. A sua volta havia mato cerrado e, aqui e acolá, apareciam algumas árvores. Uma delas em particular, uma macieira, chamou-lhe a atenção. De fato, havia enrolado nela, uma planta parasita, espécie de cipó que partindo lá de baixo a envolvia lenta e inexoravelmente. Parecia querer estrangulá-la, secá-la e estava alcançando seu objetivo, pois a parte superior da macieira já estava esquálida e sem folhagem.

Há momentos na vida em que qualquer um de nós se torna filósofo: "Eis aí um belo exemplo", pensou Hairabed. "Uma planta parasita que nem raízes tem, nada fez para crescer por si, se aproveitando de uma bela árvore, está se alimentando de graça, sem fazer nenhum esforço, sugando a sua seiva com avidez, deixando-a exaurida e seca.

Essa parasita não é o retrato do Turco e do Curdo que nem pensam em trabalhar e se aproveitam dos pobres Armênios, sugando-os, roubando-os, maltratando-os?" Hairabed era homem sensível sem grande cultura. Como conseguira tão bem essa comparação? É verdade que se não tivesse viajado, ficando na fazenda, com certeza cresceria no seu microcosmo com seus preconceitos como seus vizinhos da aldeia. (...) O destino o levara a Constantinopla, encruzilhada

5 A literatura armênia moderna é tradicionalmente dividida em Romantismo e Realismo. Enquanto Raffi é um escritor romântico, Daniel Varujan é visto como pertencente ao Realismo. Não consideramos esta distinção relevante para os propósitos do presente estudo. Estes movimentos aconteceram mais ou menos simultaneamente na Armênia, sendo que muitos escritores apresentavam tanto tendências românticas, quanto realistas, em suas obras (SAPSEZIAN, 1994 HACIKYAN, 2005)

Ainda com relação às diferenças entre estes dois escritores, cabe esclarecer que Raffi, que cresceu na Armênia Persa (posteriormente, Armênia Russa), compôs os seus textos em armênio oriental; já Daniel Varujan, que é natural da Armênia Turca, expressou-se em armênio ocidental. 
entre a Europa e a Ásia. Lá, apesar de não se fixar em nada concreto, adquirira vasta experiência que, com certeza, seus compatriotas não possuíam. (RAFFI, $1880 / 2009$, p. 53)

O filho não respondeu e o velho prosseguiu:

- "Porém em meio a todas essas desgraças, há um consolo. Por mais que roubem e saqueiem, nossos paióis estão sempre repletos, enquanto o Curdo está sempre à procura de comida."

- "Pai, o Sr. deve conhecer o provérbio: 'O ladrão nunca consegue ter a sua própria casa, mas quem tem casa pode perdê-la'. O Curdo não trabalha, não semeia, não planta e nunca tem mantimentos em sua casa. Ele se alimenta com tudo o que o Armênio tem em sua despensa, deixando-o cada vez mais pobre." (...)

- "É verdade. Há ainda mais uma coisa. Os Curdos roubam ou matam nossas ovelhas. Assim mesmo elas se multiplicam e formam grandes rebanhos. $\mathrm{O}$ lobo, apesar de matar e devorar as ovelhas está sempre com fome e nunca se multiplica. Você já viu alguma malta de lobos? O lobo é animal selvagem. Hoje, agarra uma ovelha, a mata, a come e enche a pança, mas não sabe quando e onde poderá encontrar outra oportunidade desta. Vive caçando, nem sempre encontra uma presa. Está sempre com fome. Como dizem 'um dia é da caça e o outro do caçador'. O Curdo é o lobo e nós somos as ovelhas."

A explicação do velho homem era a descrição de uma guerra sem derramamento de sangue.

- "Eu acho, pai, que se não tivessem pastores e perdigueiros para vigiar nossos rebanhos, não sobrariam mais ovelhas para contar a história. Somos, é verdade, ovelhas sem pastor, e há somente um jeito de sair dessa situação: é nos transformarmos também em lobos, desenvolvendo garras e dentes afiados." (RAFFI, 1880/2009, p. 26)

Ao voltar a cabeça, notou seu companheiro dormindo. Na penumbra, distinguia seu rosto lívido, burilado pelo cansaço, mas denotando uma determinação férrea. Tinha sono agitado. De tempo em tempo, seus lábios se moviam e ouviam-se palavras desconexas, ora em francês, ora em armênio: "Camponeses... chegou a hora...a liberdade...devem conquistá-la...com seu sangue...o presente...o futuro...a nós pertence...mostre...meus bravos...que a espada...do turco...não conseguiu acabar...com vocês...e nem com o amor pela liberdade...Para frente... meus bravos". 
"Coitado", pensou Vartan balançando a cabeça, "deve ter lido muitos livros e sonha estar nas barricadas de Paris." (RAFFI, 1880/2009, p. 58)

Khent fala da opressão, da injustiça sofrida pelo povo armênio, da violência praticada contra ele, tanto pelas tribos curdas como pelos turcos. A obra não apenas trabalha a questão da conscientização dos armênios, ela é um convite à rebelião e à revolta.

Como ilustram as citações acima, Raffi utiliza muitas parábolas: "a ovelha e o lobo" "a macieira e a planta parasita". Um de seus objetivos era conscientizar as massas, o povo simples, daí esse tipo de linguagem. Note-se, ainda, que 0 autor não simplesmente insere estas parábolas na fala de seus personagens, mas faz questão de explicá-las e esclarecê-las, como nos trechos acima, em que a ovelha representa o povo armênio, enquanto o lobo equivale a seus opressores.

Nesta obra, os curdos são descritos como nômades bárbaros que, juntamente com os turcos, raptavam as mulheres armênias e roubavam os armênios, levando tudo quanto possuíam.

Os armênios, por seu turno, são retratados como um povo trabalhador, abastado, hospitaleiro, que ama a sua terra; um camponês de vida simples que se orgulha de tirar seu sustento da terra, mas também um povo covarde, submisso, conformado demais com esta situação de opressão.

Embora esta seja uma obra ficcional, ela tem como pano de fundo um fato histórico: a guerra russo-otomana de 1877-8. Os armênios esperavam que a Rússia libertasse a Armênia ocidental do jugo do Império Otomano. Contudo, mesmo com a vitória russa na guerra, isto não aconteceu. Em vez disso, os russos adotaram uma política de hostilidade, russificação e colonização. Os intelectuais tentaram manter precariamente a unidade da nação, a igreja, a cultura, que estavam agora sujeitas a repressões políticas, culturais e econômicas dos dois Impérios. Data desta época a criação de importantes partidos políticos armênios, fundados por jovens patriotas. Muitos deles contam com a participação de autores armênios modernos (BARDAKJIAN, 2000).

Raffi exerceu grande influência sobre o pensamento político de seus contemporâneos e das gerações subsequentes, inspirando a formação de movimentos de resistência. Gulludjian (2005) nota que a criação de partidos políticos $e$ 
revolucionários armênios se iniciou imediatamente após a publicação de suas obras, e que Khent foi um livro tão influente que até mesmo o datilógrafo desta obra, tão logo terminou o seu trabalho, pediu demissão e foi se juntar à guerrilha em defesa dos direitos dos armênios da Armênia Turca.

Raffi morreu em 1888, poucos anos antes dos primeiros massacres de 1895-6. Ele, portanto, não viu o gciiocídio, mas sua obra antecipa este acontecimento em muitas passagens. É possível que a violência tenha chegado a um ponto extremo, sinalizando aos armênios que aquela situação social e política teria um fim trágico.

Um outro autor representativo desta literatura política e socialmente militante é Daniel Varujan (1884-1915). Poeta moderno, engajado como Raffi, Varujan foi um dos intelectuais armênios assassinados em 24 de abril de 1915. Como já mencionamos, há toda uma geração de escritores modernos da Armênia Turca que perdeu a vida no genocídio (Siamanto, Rupen Sevague, entre outros).

Transcrevemos, a seguir, o poema "Derenik", ilustrativo desse engajamento.

\section{Derenik}

A porta se abre; Derenik assustado

Como se fosse uma corça ferida por uma flecha

Cai chorando nos braços de sua mãe.

- "O que tu tens, filho, diz-me rápido... não chores,

- A cobra te mordeu, ou o cavalo te deu um coice?"

- "Cortou-me a cabeça o vizinho Alí..."

E mostra a ferida debaixo de seus cachos negros,

Donde manava o sangue,

Cobrindo essa cabeça armênia com ódio turco.

$\mathrm{Na}$ alma da brava mãe

Abrem-se abismos plenos de vergonha.

É prudente afagar sobre o peito

A testa vencida do medroso?

Surda a sua piedade, por um momento,

Afasta de seu peito a cabeça

Desse pequeno covarde e grita: 
- "Fora!... Até que não vás e limpes

- Teu sangue com o dele,

- Hoje não voltes para casa, traidor de meus cuidados,

- Acaso te alimentaste com pão de aveia?... Fora!”

Rubra de vergonha, a criança argumenta:

- "Mas, mãe, Alí é filho de turco,

- Tem ódio em seus olhos e sabre em sua cintura."

- "Tu, também, és filho de armênio, que esteja em tua cintura

- Minha tesoura, minha roca, o que queiras... Fora!"

Envergonhado, olhando para o chão,

Sai Derenik, silenciosamente...

Lá, perto de uma árvore, vejo-o à luz da lua,

Com uma pedra na mão, nervoso, pálido,

(enquanto o sangue goteja em suas bochechas)

Na soleira do inimigo, espera longamente... (VARUJAN, In: SARAFIAN, 1983, p.158-9, tradução minha)

Neste poema, a mãe, quando descobre que o ferimento do filho foi causado pelo vizinho turco, muda completamente de atitude. Ela imediatamente para de consolar a criança e se mostra fria e cruel. Surda para sua piedade, diz-lhe: não volte aqui enquanto não se vingar, enquanto não lavar o seu sangue com o dele. A mãe, com esta atitude, deseja criar um guerreiro, um combatente, e não um homem covarde, servil, que aceita a violência passivamente.

Este poema é, portanto, outro texto que ilustra esta literatura moderna política e socialmente engajada, uma literatura patriótica, militante, que buscava esclarecer e conscientizar o povo, para que este lutasse contra a exploração e violência que vinha sofrendo.

Cabe notar que as ações militantes e revolucionárias armênias são tomildas como um dos "motivos" para o genocídio. ${ }^{6}$ De fato, pode-se dizer que a

6 As açōes militantes e revolucionárias armênias, as divergências religiosas, o nacionalismo turco e a Primeira Guerra Mundial (quando uma parte dos armênios da região ocidental se recusa a lutar na guerra ao lado da Turquia, enquanto na região oriental formam-se grupos de voluntários 
militância armênia foi uma das razões que levaram Abdul Hamid, que ficou conhecido como o "sultão vermelho", a realizar os primeiros massacres no final do século XIX, entre os anos de 1895 e 1896, quando morreram cerca de 200 mil armênios. Contudo, a diplomacia, a espera pela intervenção das grandes potências, a paciência e a espera pelas reformas já vinham sendo uma estratégia adotada pelo povo armênio, a qual não tinha trazido resultado algum. Houve uma série de tratados assinados nesta época entre a Turquia e as nações europeias, para garantir melhores condições de vida para os armênios da Armênia Turca, mas estes tratados não saíram do papel, ou seja, eles não tiveram efeito.

Na Armênia Turca, o marco trágico que foi o genocídio implicou a morte ou o exílio de toda uma geração de escritores modernos. De modo que a continuidade dessa literatura que era escrita em língua armênia ocidental (o armênio que se falava na Armênia Turca) vai ter de se dar nas condições da diáspora. É a partir daí que se origina, portanto, a literatura armênia contemporânea da diáspora.

Na região oriental, por seu turno, em 1918, há a criação de uma República Armênia independente; contudo, essa independência dura somente dois anos. Em 1920, dá-se a sovietização: a Armênia passa a ser uma das Repúblicas Socialistas da União Soviética, dominação que se estende até 1991, quando, com a queda da URSS, a Armênia finalmente conquista a sua independência.

Os escritores da Armênia Russa tiveram então que enfrentar grandes adversidades, mas tinham uma vantagem sobre os escritores da diáspora: eles ainda pisavam solo armênio. Assim, contavam com um público leitor. Como nota Sapsezian (1994), a Armênia sovietizada continha uma população estável, no seio da qual a língua, a literatura e a cultura armênias podiam ser cultivadas. Isto não acontecia na diáspora, já que nesta o escritor constituía “uma voz que clama no deserto" (SAPSEZIAN, 1994, p.140), produzindo textos que ele nem sequer sabia se seriam lidos.

armênios para combater ao lado dos russos) são tomados como possíveis motivações para o genocídio. A nosso ver, porém, nada pode justificar um genocídio. Por esta razão, utilizamos o termo "motivos" entre aspas. 
$\mathrm{Na}$ época atual, em que não há mais uma Armênia Turca e uma Armênia Russa, mas sim uma Armênia independente, com cerca de 3,5 milhões de habitantes, e a diáspora armênia espalhada pelo mundo, convencionou-se dividir a literatura armênia em duas vertentes: a produzida na Armênia e a produzida na diáspora (cf. SAPSEZIAN, 1994; KEROUZIAN; DINIZ, 1979). ${ }^{7}$

Todos os autores cujos escritos aparecem depois do genocídio de 1915, sejam eles da Armênia ou da diáspora, fazem parte do período contemporâneo da literatura armênia (SAPSEZIAN, 1994).

Essa diáspora armênia do século XX é consequência direta do genocídio. Ela se originou a partir dos refugiados, sobreviventes que escaparam desse massacre. Hoje, estima-se que são aproximadamente 4 milhões de pessoas (KERIMIAN, 2005), entre armênios e descendentes de armênios, espalhados por praticamente todas as regiões do globo. ${ }^{8}$

Essas pessoas que vivem na diáspora não romperam totalmente os laços com a Armênia. Elas estabeleceram comunidades armênias em diversas partes do mundo. Tais comunidades procuram manter vivas as tradições, os costumes, a literatura e a língua armênias fora da mãe-pátria. É neste contexto que surgem os escritores da diáspora.

Mas essa literatura armênia produzida na diáspora é um assunto que desperta controvérsia. Primeiramente pelo aspecto geográfico: trata-se de uma literatura produzida fora da Armênia. Muitos críticos se mostram céticos quanto a este tipo de criação literária, argumentando que uma literatura nacional só pode ser produzida em território nacional. Somente assim pode ela nutrir-se dos valores, tradição e cultura próprios de seu país.

Em segundo lugar, esses críticos questionam o aspecto linguístico. A literatura armênia da diáspora é escrita não somente em língua armênia, mas também em outras línguas (espanhol̉, inglês, francês, etc.). Este é um argumento difícil de ser refutado: como classificar como literatura armênia textos compostos em outros idiomas, que não o próprio armênio?

\footnotetext{
8 Sapsezian (1994) faz ressalvas a esta separação, mas a utiliza em sua obra.

8 Há grande variação nesses números, conforme a fonte consultada. É importante ressaltar que se trata sempre de uma estimativa, porque seria necessário verificar quantos desses descendentes se declaram armênios, reconhecendo essa identidade.
} 
Um último aspecto que geralmente costumava ser colocado é que esta literatura da diáspora teria um caráter provisório e esporádico. Os críticos argumentavam que poderiam surgir algumas criações literárias, mas que estas não subsistiriam ao longo do tempo.

Esta última questão está ligada à própria diáspora como um todo. Muitos não acreditavam que ela fosse ter um caráter permanente; deduziam que seus integrantes passariam por um processo de assimilação cultural.

Hoje, quase cem anos após o genocídio, poucos integrantes da diáspora são provenientes da Armênia. A maioria constitui descendentes de imigrantes armênios. Mas, ao contrário do que se esperava, eles continuam a manifestar sinais de sua identidade armênia.

A literatura armênia produzida por esses habitantes da diáspora gerou um patrimônio literário de valor, tanto do ponto de vista quantitativo quanto qualitativo. De modo que, atualmente, não se pode mais questionar a existência dessa literatura armênia produzida fora da Armênia (SAPSEZIAN, 1994).

Em grande parte, são obras autobiográficas. Estes autores vão falar do trauma do genocídio e da expatriação, do biculturalismo e do bilinguismo característicos da diáspora armênia, mas a temática dominante no trabalho dos escritores da diáspora é a busca por suas raízes, por sua identidade armênia. Mais do que isto, eles tratam de uma questão complicada: como ser ou manter-se um armênio na diáspora? Esta é ainda uma questão atual, que se aplica não só aos escritores, mas aos habitantes da diáspora de modo geral.

Para exemplificar a literatura armênia contemporânea, produzida na diáspora e escrita em línguas estrangeiras, citamos aqui dois de seus mais reconhecidos autores: William Saroyan e Michael J. Arlen.

William Saroyan (1908-81) nasceu em Fresno, Califórnia, nos Estados Unidos. Ele era descendente de emigrantes da Armênia Turca, em outras palavras, filho de sobreviventes do genocídio. Suas obras descrevem o meio ambiente americano, mas frequentemente contêm um personagem armênio, ou referências a elementos do universo armênio.

No trecho a seguir, retirado do conto "70 mil assírios", dialogam dois personagens americanos: um descendente de armênio e outro descendente de assírio. 
"Este nome", eu disse, "Badal. Você é um armênio?"

Eu sou um armênio. Eu já mencionei isto antes, as pessoas me olham e ficam curiosas, então eu me apresento e digo para elas. "Eu sou um armênio", eu digo. Ou elas leram algo que escrevi e começam a se perguntar, então eu as deixo saber. "Eu sou um armênio", eu digo. Isto é um comentário sem sentido, mas como elas esperam que eu o diga, então eu assim o faço. Não tenho ideia de como é ser um armênio, ou como é ser um homem inglês, ou japonês, ou qualquer outro. Tenho uma vaga ideia de como é estar vivo.

(...)

"Você é um armênio?", eu perguntei.

Nós somos um povo pequeno e sempre quando um de nós encontra o outro, isto é um evento. Nós estamos sempre procurando em volta por alguém com quem falar em nossa língua.

(...)

Eu perguntei a Theodore Badal se ele era um armênio.

Ele disse, "eu sou um assírio".

Bom, isto era algo. Eles, os assírios, vieram da nossa parte do mundo, eles tinham narizes como nossos narizes, olhos como nossos olhos, corações como nossos corações. Eles tinham uma língua diferente. Quando eles falavam, nós não podíamos entendê-los, mas eles se pareciam muito conosco. Não foi tão prazeroso quanto seria se Badal fosse um armênio, mas era algo.

Badal disse, "Eu não posso ler assírio. Eu nasci no velho país, mas eu quero me livrar dele".

Ele parecia cansado, não fisicamente, mas espiritualmente.

"Por quê?", eu disse. "Por que quer se livrar dele?"

"Bom", ele riu, "simplesmente porque tudo está fracassado por lá". E eu estou repetindo suas palavras de um modo preciso, não estou acrescentando nada meu. "Nós uma vez fomos um grande povo", ele continuou. "Mas isto foi ontem, antes de ontem. Agora somos um tópico de história antiga. Nós tínhamos uma grande civilização. Eles ainda a estão admirando. Agora eu estou na América aprendendo a cortar cabelo. Nós fomos banidos como uma raça. Nós estamos acabados, tudo está acabado, por que deveria eu aprender a ler a língua? Nós não temos escritores, nós não temos notícias." [...] Estes comentários eram muito 
dolorosos para mim, um armênio. Eu sempre me senti mal por meu próprio povo ser destruído. Eu nunca tinha ouvido um assírio falando em inglês sobre estas coisas. Eu senti um grande amor por esse jovem companheiro. (SAROYAN, 1934, p.33-8, tradução minha)

Os assírios e os armênios eram povos guerreiros e conquistadores na Antiguidade. Eles lutaram entre si por cerca de trezentos anos e conseguiram formar vastos impérios. A extensão territorial atual da Armênia, $29.800 \mathrm{~km}^{2}$, representa somente $10 \%$ do território que chegou a ocupar na Antiguidade.

Num tom saudosista, o trecho acima contrasta o passado grandioso com o presente do habitante da diáspora, na qual a sua identidade corre o risco de se perder. Diferentemente dos armênios, os assírios não conseguiram sobreviver como uma nação, como um Estado, mas muitas pessoas ainda se denominam assírias, reconhecendo essa origem, mesmo nos dias atuais.

Contemporâneo de Saroyan, Michael J. Arlen (1930-) é um escritor de nacionalidade inglesa. Trata-se de um armênio que redescobre sua identidade, a qual tinha permanecido um mistério aos seus próprios olhos até sua vida madura.

Arlen é da terceira geração, isto é, neto de sobrevivente. Seu pai negou a identidade armênia, abandonando seu nome armênio e adotando outro nome, e não lhe transmitiu nada sobre a cultura, a história e a língua armênias. Ainda assim, Arlen procura saber sobre suas origens armênias e se aproxima espontaneamente da comunidade armênia, aprendendo sobre a língua, a história, os costumes e as tradições de seus ancestrais.

Em seu livro autobiográfico Passagem para Ararat, ele narra esta busca por sua identidade armênia. Vejamos alguns trechos da obra:

Numa determinada época de minha vida, parti numa viagem para descobrir por mim mesmo o que significa ser um armênio. Porque, apesar de ser armênio, ou meio armênio, até então eu nada sabia sobre os armênios ou a Armênia. [...]

Foi numa escola inglesa, quando tinha nove anos, que compreendi pela primeira vez que eu próprio era de um modo ou de outro um armênio - ou, pelo menos, meio armênio. Antes da Segunda Guerra Mundial morávamos na Europa - expatriados ingleses no sul da França. Mas, se naqueles dias eu tinha alguma 
ideia sobre identidade, pensava que era inglês, nós éramos ingleses. Falávamos inglês, viajávamos com passaportes ingleses.

[...] por causa da guerra, mudamo-nos para a América, e tornei-me cada vez mais, e, finalmente, aos vinte e um anos de idade, cidadão americano. Geralmente sentia-me americano,, ou talvez durante algum tempo anglo-americano, mas, obviamente, havia algo que estava faltando. Estava faltando ou havia sido adicionado. Percebi ser acompanhado por uma espécie de sombra por "ser armênio", que outras pessoas às vezes notavam, ou comentavam casualmente, mas que meu pai dissera, de fato, não existir. (ARLEN, 1978, p. 7-9).

No trecho acima transparece a identidade do armênio como cidadão do mundo (cf. HAMALIAN, 1980). Arlen é um exemplo típico: é de origem armênia; é inglês (nasceu na Inglaterra); vive parte de sua vida na França e depois se fixa nos Estados Unidos. Isto pode ser visto como um benefício: é a imagem do armênio como cidadão do mundo, aquele que se estabelece nos mais diferentes países, o que lhe proporciona uma rica experiência cultural. Contudo, isto igualmente pode gerar uma confusão no que se refere à identidade. "Como você se define?" é ainda uma questão atual para os descendentes de armênios da diáspora.

Arlen (1978) finaliza esta obra com uma reflexão: os armênios foram uma nação, antes mesmo de o mundo pensar em nações ou nacionalidade, do modo como entendemos estes conceitos modernamente. Mais do que isto, os armênios tiveram que ir além da nacionalidade. Isto porque o conceito de nacionalidade está fortemente ligado à noção de território - ser uma nação é herdar, ou fazer parte de um território -, e os armênios da diáspora tiveram que passar por cima disto.

A literatura armênia contemporânea da diáspora reflete esta contradição: trata-se de uma literatura que é produzida, não no território da Armênia, mas em outros países, por autores que não têm nacionalidade armênia e que se expressam, não em língua armênia, mas em línguas estrangeiras.

Não obstante esta contradição, ou mesmo por causa dela, os textos desses autores fazem referência a diversos elementos do universo armênio. Eles narram a adaptação dos imigrantes nas condições da diáspora e a busca pessoal dos descendentes por suas raízes, por sua identidade armênia. 


\section{Referências bibliografias}

ARLEN, M. J. Passagem para Ararat (trad. de Ana Teresa J. Reynaud). Rio de Janeiro: Paz e Terra, 1978.

BARDAKJIAN, K. B. A Reference Guide to Modern Armenian Literature 1500-1920. Detroit: Wayne State University Press, 2000.

GULLUDJIAN, H. “Nineteenth-Century Armenian Historical Fiction”. In: HACIKYAN, A. J. (coord.). The Heritage of Armenian Literature. Volume III: From the Eighteenth Century to Modern Times. Detroit: Wayne State University Press, 2005.

HACIKYAN, A. J. (coord). The Heritage of Armenian Literature. Volume III: From the Eighteenth Century to Modern Times. Detroit: Wayne State University Press, 2005.

HAMALIAN, L. As others see us: The Armenian Image in Literature. New Yor: Ararat Press, 1980.

KERIMIAN, N. Massacre de armênios. São Paulo: Comunidade da Igreja Apostólica Armênia do Brasil, 1998.

KERIMIAN, S. Entrevista sobre a diáspora armênia concedida no canal $48 \mathrm{em}$ $11 / 06 / 2005$.

KEROUZIAN, Y. O.; DINIZ, B. As grandes datas da Literatura Armênia. São Paulo: FFLCH/USP, 1979.

MARTINS, A. H. C. “../../.././Documents and Settings/ufflch/Configurações locais/ usuario/Meus documentos/Clinger/Nova Revista/10_1_campolina2.pdf, Armênia, um povo em luta pela liberdade: o mais longo genocídio da história”. Ética e Filosofia, edição especial, junho de 2007. Publicação eletrônica: <www.eticaefilosofia.ufjf.br>.

RAFFI. Khent. (tradução de Charles Apovian). 1880/2009, publicação eletrônica: $<$ http://www.armenia.brasil.nom.br>.

SAPSEZIAN, A. História da Armênia. Rio de Janeiro: Paz e Terra, 1988.

Literatura Armênia. Rio de Janeiro: Paz e Terra, 1994.

SARAFIAN, J. Armênia atravs de sus poetas. Buenos Aires: I.G.A., 1983.

SAROYAN, W. "Seventy thousand Assyrians". In: SAROYAN, W. The Daring Young Man on the Flying Trapeze and Other Stories. New York: New Directions Books, 1934. "70 Mil Assírios", tradução de Deize C. Pereira (inédita).

TOYNBEE, A. Atrocidades Turcas na Armênia: Denúncias de grandes personalidades. São Paulo: Paz e Terra, 1916/2003. 